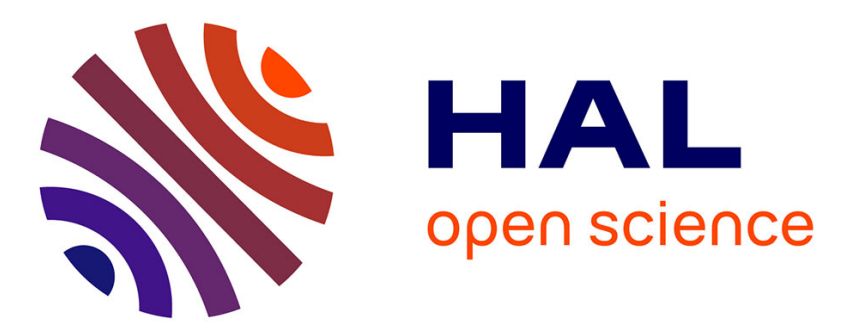

\title{
A Practical Two-Stage Algorithm for Retrieving Land Surface Temperature from AMSR-E Data-A Case Study Over China
}

Fang-Cheng Zhou, Zhao-Liang Li, Hua Wu, Si-Bo Duan, Xiaoning Song, Guangjian Yan

\section{To cite this version:}

Fang-Cheng Zhou, Zhao-Liang Li, Hua Wu, Si-Bo Duan, Xiaoning Song, et al.. A Practical Two-Stage Algorithm for Retrieving Land Surface Temperature from AMSR-E Data-A Case Study Over China. IEEE Journal of Selected Topics in Applied Earth Observations and Remote Sensing, 2018, 11 (6), pp.1939-1948. 10.1109/JSTARS.2018.2799552 . hal-02377727

\section{HAL Id: hal-02377727 \\ https://hal.science/hal-02377727}

Submitted on 4 Dec 2020

HAL is a multi-disciplinary open access archive for the deposit and dissemination of scientific research documents, whether they are published or not. The documents may come from teaching and research institutions in France or abroad, or from public or private research centers.
L'archive ouverte pluridisciplinaire HAL, est destinée au dépôt et à la diffusion de documents scientifiques de niveau recherche, publiés ou non, émanant des établissements d'enseignement et de recherche français ou étrangers, des laboratoires publics ou privés. 


\title{
A Practical Two-Stage Algorithm for Retrieving Land Surface Temperature from AMSR-E Data-A Case Study Over China
}

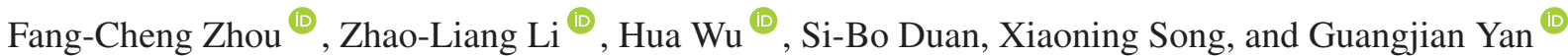

\begin{abstract}
Land surface temperature (LST) is an important parameter that directly affects the water and heat balance between the Earth surface and atmosphere. Mapping the LST distribution at continuous temporal and wide spatial scales is very helpful for researching many physical and biochemical processes. Remotely sensed instruments are the key players in these studies. Passive microwave remotely sensed data have the advantage of retrieving the land parameters under nearly all weather conditions because of the power to penetrate clouds. In this study, a practical two-stage algorithm, which uses single-frequency and double-polarization passive microwave brightness temperature observations, is presented to retrieve the LST over China. The vertically polarized land surface emissivity (LSE) at $18.7 \mathrm{GHz}$ is first estimated by a parameterization relationship with the polarization ratio (PR), which is defined as the ratio of the horizontal to the vertical brightness temperatures at the same frequency. Subsequently, the LST is retrieved using the estimated LSE by ignoring the atmospheric effect. The evaluation of the simulated data shows an RMSE of $1.45 \mathrm{~K}$, which is very encouraging. The cross validations by the satellite thermal infrared products are from daily to monthly time scales. The daily accuracy is $3.04 \mathrm{~K}$ and the bimonthly accuracy
\end{abstract}

Manuscript received September 15, 2017; revised December 25, 2017; accepted January 18, 2018. Date of publication February 27, 2018; date of current version June 29,2018. This work was supported by the National Natural Science Foundation of China under Grant 41471297, Grant 41331171, Grant 41531174, and Grant 41601603. (Corresponding author: Hua Wu.)

F.-C. Zhou is with the State Key Laboratory of Resources and Environmental Information System, Institute of Geographic Sciences and Natural Resources Research, Chinese Academy of Sciences, Beijing 100101, China, and also with the University of Chinese Academy of Sciences, Beijing 100049, China (e-mail: zhoufc.14b@igsnrr.ac.cn).

$\mathrm{H}$. Wu is with the State Key Laboratory of Resources and Environment Information System, Institute of Geographic Sciences and Natural Resources Research, Chinese Academy of Sciences, Beijing 100101, China, and also with the University of Chinese Academy of Sciences, Beijing 100049, China, and also with the Jiangsu Center for Collaborative Innovation in Geographical Information Resource Development and Application, Nanjing 210023, China (e-mail: wuhua@igsnrr.ac.cn).

Z.-L. Li is with the Key Laboratory of Agricultural Remote Sensing, Ministry of Agriculture/Institute of Agricultural Resources and Regional Planning, Chinese Academy of Agricultural Sciences, Beijing 100081, China, and also with ICube, UdS, CNRS, Illkirch 67412, France (e-mail: lizl@unistra.fr).

S.-B. Duan is with the Key Laboratory of Agricultural Remote Sensing, Ministry of Agriculture/Institute of Agricultural Resources and Regional Planning, Chinese Academy of Agricultural Sciences, Beijing 100081, China (e-mail: duansibo@caas.cn).

$\mathrm{X}$. Song is with the University of Chinese Academy of Sciences, Beijing 100049, China (e-mail: songxn@ucas.ac.cn).

G. Yan is with the State Key Laboratory of Remote Sensing Science, School of Geography, Beijing Normal University, Beijing 100875, China (e-mail: gjyan@ bnu.edu.cn).

Color versions of one or more of the figures in this paper are available online at http://ieeexplore.ieee.org.

Digital Object Identifier 10.1109/JSTARS.2018.2799552 is $4.43 \mathrm{~K}$. A high positive bias in arid and semiarid regions and a negative bias in frequently cloudy regions are noticeable in both comparisons. These biases do not reveal the uncertainties of this LST retrieval algorithm; on the contrary, the retrieved the Advanced Microwave Scanning Radiometer - EOS (AMSR-E) LST appears to be more reasonable compared to the thermal infrared LST under certain circumstances.

Index Terms-Land surface emissivity (LSE), land surface temperature (LST), MODIS, polarization ratio (PR), roughness index (RI).

\section{INTRODUCTION}

$\mathbf{L}$ AND surface temperature (LST) is the direct driving force in the interaction between long-wave radiation and turbulent heat fluxes at the surface-atmosphere interface, which dominates the biochemical and physical process between the Earth surface and atmosphere [1]-[4]. The LST is also an important input parameter in many models used for evaluating the water and heat balance components at local and global scales, and the more accurate the LST, the higher the evaluation accuracy [5]. Additionally, the researchers [6] found that strong diurnal signals of soil moisture content and $\mathrm{CO}_{2}$ concentration exist in desert regions mainly due to the LST cycle between day and night, which can explain much of the carbon-imbalance at a global scale [7]. As a result, the rapid and continuous measurement of LST is meaningful in many fields. Although the LST is recognized as a high priority parameter by the International Geosphere and Biosphere Program (IGBP) [8], the numbers of weather stations which can measure this parameter are not enough for the applications at a large scale [9]-[13]. Compared with finite weather stations, remotely sensed technology has been considered as the only way to monitor the LST at regional or global scales because of its great spatial representation [14].

Currently, the most common remotely sensed technology for retrieving LST is from thermal infrared observations, which includes a series of mature methods and relatively high accuracies [15]-[20]. However, the biggest limitation of infrared technology is that it can only be used in cloud-free conditions. Even the thin clouds or aerosol (dust) contamination can highly affect the measurement accuracy of LST [21]. The Earth is covered in clouds approximately $60 \%$ of the time [22], and this is even higher in tropical forest areas [14]. It means that the remotely sensed LST products from infrared observations are fragmen- 
tary most of the time. In contrast, with longer wavelengths, the ability to penetrate clouds is one of the biggest advantages of using passive microwave remote sensing for retrieving the LST [7].

The LST is not a directly available variable from passive microwave remote sensing observations. In the process of inversion, from the brightness temperature observations to the LST, the land surface emissivity (LSE) is the other key parameter tightly coupled with LST and affected by many factors (e.g., soil moisture content, soil texture, soil roughness, and proportion and physical properties of vegetation or snow) [23]. Due to the mutability of these influencing factors at both spatial and temporal scales, it is hard to directly measure the LSE using ground-based instruments or by forward modeling methods at the satellite footprint scale [24]. A simple method is that LSE is derived from brightness temperature observations through the atmospheric contribution and the modulation by LST removed [25]-[27]. Global LSE retrievals were first developed by Prigent et al. [25] using the brightness temperature observations from the Special Sensor Microwave Imager (SSM/I). Other available products later were proposed from other remote sensors, such as the Advanced Microwave Scanning Radiometer - Earth Observing System (AMSR-E) [27], [28], the Advanced Microwave Sounding Unit (AMSU) [29], the Tropical Rainfall Measuring Mission (TRMM) Microwave Imager (TMI) [30], the Windsat [31], and the Advanced Microwave Scanning Radiometer 2 (AMSR2) [32]. These methodologies have been proven to provide reliable first-order emissivity estimates for practical use in operational algorithms [33]. Nevertheless, due to the usage of infrared LST products in these algorithms, the daily emissivities under cloudy conditions are normally missing. Hence, the timescales of these LSE products are almost monthly [34]. However, for the retrieval of instantaneous LST, the instantaneous LSE is more valuable than the monthly LSE because an error of 0.01 for the estimated emissivity can lead to a $3 \mathrm{~K}$ error in the retrieved LST. Consequently, it would be very helpful for the improvement of the retrieval accuracy of the LST if the measurement of the LSE is instantaneous and accurate.

The goal of this study is to develop a practical, two-stage, all-weather LST retrieval algorithm. In the first stage, a parameterization relationship between the polarization ratio $(\mathrm{PR}$, defined as the ratio of the horizontal to vertical brightness temperatures at the same frequency) and the vertically polarized LSE is built to estimate the latter from the former. In addition, the estimated LSE is used to retrieve the LST during the second stage. The study is organized as follows: Section II describes the simulated and remotely sensed data employed in this study. Section III proposes the two-stage LST retrieval algorithm. The evaluation results and discussions are presented in Section IV. Conclusions are drawn in Section V.

\section{DATA}

\section{A. Simulated Data}

Compared with field experiments, simulation experiments can cover many situations and be more representative and controllable. To simulate the actual environment as much as possible, a dataset of simulated brightness temperature data, which covers a wide range of land surface and atmospheric conditions, are built by the radiative transfer model. The land surface conditions include LST from 275 to $330 \mathrm{~K}$ in steps of $5 \mathrm{~K}$, soil moisture contents from $2 \%$ to $40 \%$ in steps of $2 \%$, sand volume fractions of soil from $0 \%$ to $60 \%$ in steps of $20 \%$, and clay volume fractions of soil from $0 \%$ to $60 \%$ in steps of $20 \%$ (the sum of sand and clay volume fractions less than or equal to $100 \%)$. With these land surface parameters, an empirical model proposed by Wang and Schmugge [35] is used to estimate the complex dielectric constants of land surfaces. Considering the effect of roughness caused by the actual fluctuating surface on the LSE [36], [37], the land surface roughness parameters, correlation length (cl), and root-mean-square (RMS) height also need to be ergodic. This study references the data from Wigneron et al. [38] who created seven plots of varying surface roughness conditions from a rough freshly plowed field (RMS height of $59.37 \mathrm{~mm}$ and $\mathrm{cl}$ of $67.32 \mathrm{~mm}$ ) to a very smooth surface (RMS height of $4.57 \mathrm{~mm}$ and $\mathrm{cl}$ of $206.06 \mathrm{~mm}$ ). The cl varies from 60 to $210 \mathrm{~mm}$ in steps of $30 \mathrm{~mm}$ and RMS height varies from 4 to $67 \mathrm{~mm}$ in steps of $3 \mathrm{~mm}$. Afterward, all the earlier parameters, frequency $(18.7 \mathrm{GHz})$ and incidence angle $\left(55^{\circ}\right)$ of the AMSR$\mathrm{E}$ are input to the Advanced Integral Equation Model (AIEM) [39]-[41] to simulate the LSE of soil with both vertical and horizontal polarizations. To simulate the effect of vegetation on the surface emission, a simple simulation is performed, in which the vegetation is assumed to be a homogeneous layer over the soil layer with three key parameters: vegetation temperature, single scattering albedo, and vegetation optical depth. Vegetation temperature is assumed to be equal to LST, and the single scattering albedo and vegetation optical depth are given the default values of 0.09 and 0.1 , respectively [42]. On cloud-free days, the precipitable water vapor (PWV) content is the main influencing factor of the atmospheric effect in the process of microwave radiation passing through the atmosphere. Consequently, four atmospheric profiles with different total PWV contents $(8.47$, $14.06,28.80$, and $40.36 \mathrm{~mm}$, respectively) are selected as the representative atmospheric profiles from the Thermodynamic Initial Guess Retrieval (TIGR) dataset, which was constructed at the Dynamic Meteorology Laboratory and includes 2311 atmospheric profiles selected from 80000 radiosonde datasets. Each atmospheric profile records temperature, water vapor and ozone concentrations on a given pressure grid from the surface to the top of the atmosphere. These atmospheric profiles are the input for the Monochromatic Radiative Transfer Model (MonoRTM) to estimate the atmospheric transmission and upwelling and downwelling atmospheric emissions. MonoRTM is a radiative transfer model designed to process many monochromatic wavenumber values, which is particularly useful for the microwave spectrum. Meanwhile, considering that the aim of this study is to develop an all-weather LST retrieval algorithm, the cloud liquid water (CLW) content as the key parameter of clouds is also artificially added to each atmospheric profile and varies from 0.00 to $0.28 \mathrm{~mm}$ in steps of $0.07 \mathrm{~mm}$ in this study. This dataset can represent a large majority of the natural land surface and atmospheric conditions and helps us to develop the all-weather LST retrieval algorithm. 


\section{B. Passive Microwave Remotely Sensed Data}

AMSR-E is a dual-polarized passive microwave radiometer, which operates at frequencies of $6.9,10.7,18.7,23.8,36.5$, and 89.0 GHz. AMSR-E L2A global swatch spatially resampled brightness temperature data are available from Jun. 1, 2002 to Oct. 4, 2011 on the NASA Distributed Active Archive Center (DAAC) at the National Snow and Ice Data Center (NSIDC); it provided twice-daily measurements of global microwave emissions over land with descending/ascending orbital equatorial crossings at $0130 / 1330$ local solar time. In this study, the spatially resampled $\left(0.25^{\circ}\right)$ brightness temperature data at $18.7 \mathrm{GHz}$ of AMSR-E are chosen as the study data.

\section{Thermal Infrared Remotely Sensed LST Products}

In consideration of the AMSR-E and MODIS radiometers onboard the same satellite-Aqua that share the same overpass time, MODIS thermal infrared LST products are used during clear days as the validation data, which is known as one of the most reliable global LST remotely sensed products [17]-[19]. Validated by in situ measurements, MODIS clearday LST products show an accuracy of within $1 \mathrm{~K}$ over some lakes and land sites [43]-[45]. However, in consideration of the difficulty in validating the daytime LST products over land sites because of the high spatial variations in the in situ data [44], the version 6 cloud-free LST nighttime products (MYD11C1) are finally chosen as the validation data because of the higher accuracy and reliability. MYD11C1 has a spatial resolution of $0.05^{\circ}$ and overpass time of 0130 local solar time (descending). In addition, the chosen data are required to have the best quality to limit the cloud contamination in the thermal infrared data. To be consistent with the AMSR-E brightness temperature data, the pixel scales of MYD11C1 are further scaled up to $0.25^{\circ}$.

\section{In Situ LST Observations}

Single-point surface temperature measurements are also used to validate the accuracy of the proposed algorithm. The surface air temperature measurements taken every 6 hours (at 0200, 0800, 1400, 2000 local solar time) at 728 meteorological stations on mainland China between 1981 and 2010 are provided by the National Meteorological Information Center of China's Meteorological Administration (www.nmic.gov.cn). Daily minimum temperature measurements (assumed at 0200 local solar time) are used to validate the retrieved descending LST at 0130 local solar time and ignore the change in the LST from 0130 to 0200.

\section{E. Auxiliary Data}

The AMSR-E monthly microwave LSE products at $18.7 \mathrm{GHz}$ with vertical and horizontal polarizations are chosen to help screen out the study area (more on this later). The AMSR-E monthly emissivity products are derived from the radiative transfer model with the ancillary data [27], [28]. The ancillary data include LST, cloud mask data, and atmospheric parameters. The LST and cloud mask data are obtained from the International Satellite Cloud Climatology Project (ISCCP). Atmospheric parameters are obtained from the TIROS Operational Vertical Sounder (TOVS) observations to calculate the upwelling and downwelling atmospheric emissions and the atmospheric transmission.

The MODIS land cover type yearly product (MCD12) is also used to help screen out the study area (more on this later). Although an ideal algorithm should be suitable for all land cover types, it is difficult to realize it in the passive microwave region, in which the snow, ice and water land cover types have different dielectric properties compared to soil. For example, the microwave signature over snow may vary between a blackbody behavior for wet snow to high reflectivities associated with strong volume scattering by a very inhomogeneous snowpack [46], [47], and the water contamination in the field of view is particularly relevant in the case of the emissivity estimation since water presents values $(\sim 0.4)$ much lower than land $(\sim 0.9)[21]$.

\section{MEthodology}

\section{A. Frequency Selected}

Radiations at low frequencies $(6.9$ and $10.7 \mathrm{GHz})$ are easily affected by radio frequency interference (RFI) and more sensitive to soil moisture content and surface roughness than LST [42]. That is why we do not choose 6.9 or $10.7 \mathrm{GHz}$. Generally, 18.7 or $36.5 \mathrm{GHz}$ brightness temperature data is often used in single-channel LST retrieval algorithms [48], [49]. To determine which one needs less auxiliary data, comparisons of the atmospheric effects on top of the atmosphere (TOA) brightness temperature between 18.7 and $36.5 \mathrm{GHz}$ are completed with the given LST (from 275 to $330 \mathrm{~K}$ in steps of $5 \mathrm{~K}$ ), LSE and 4 atmospheric profiles (PWV of 8.47, 14.06, 28.80, and $40.36 \mathrm{~mm}$, respectively), which are both with and without CLW $(0.28 \mathrm{~mm})$. Differences between land surface and TOA brightness temperature are considered as the effects of the atmosphere (see Fig. 1). As seen in Fig. 1, the atmospheric effects of $18.7 \mathrm{GHz}$ under both clear and cloudy conditions are approximately $1 \mathrm{~K}$. However, the atmospheric effect on $36.5 \mathrm{GHz}$ changes from approximately $1 \mathrm{~K}$ in the clear-sky to approximately $4 \mathrm{~K}$ under cloudy conditions, which means that the CLW has an obvious effect on $36.5 \mathrm{GHz}$. It may create large errors if the atmospheric profile data are ignored for $36.5 \mathrm{GHz}$. Consequently, $18.7 \mathrm{GHz}$ may be more suitable for usage with the single-channel LST retrieval algorithm.

\section{B. LST Retrieval Algorithm}

Gao et al. [14] once proposed a practical LST retrieval algorithm that first requires estimation of the horizontally polarized emissivity and then derives the LST with (1):

$$
T_{s}=\frac{T_{B 18, p}}{e_{18, p}}
$$

where $T_{B 18, p}$ is the brightness temperature with $p$ the polarization (Kelvins, hereafter referred as $\mathrm{K}$ ); $e_{18, p}$ is the emissivity with $p$ the polarization, here $p$ stands for horizontal polarization; and $T_{s}$ is the LST $(\mathrm{K})$. The reason for choosing the horizontally polarized channel is that $e_{18, h}$ can be expressed as a function of the PR. Therefore, the retrieval algorithm can work without the auxiliary data. 


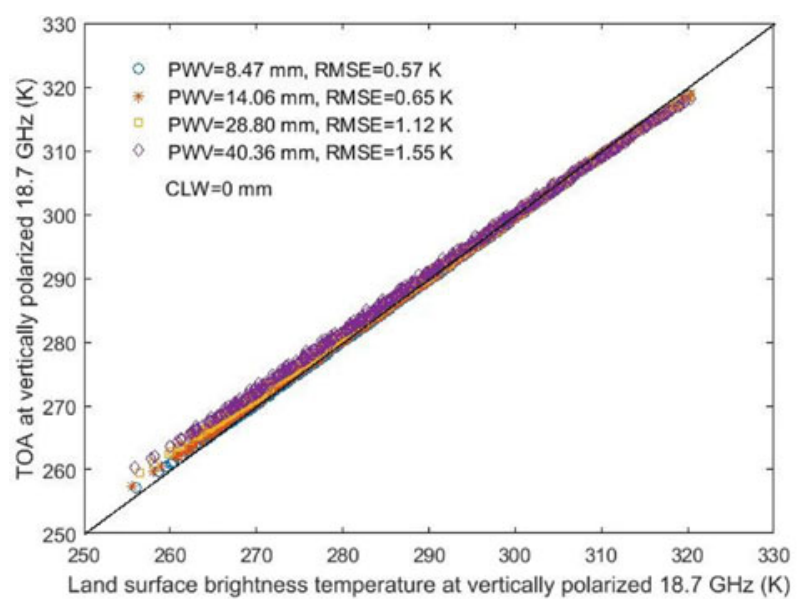

(a)

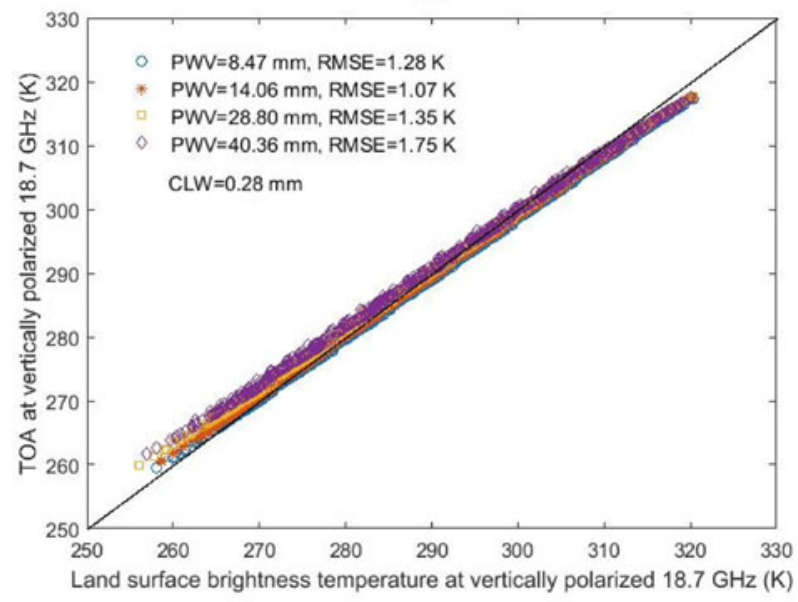

(b)

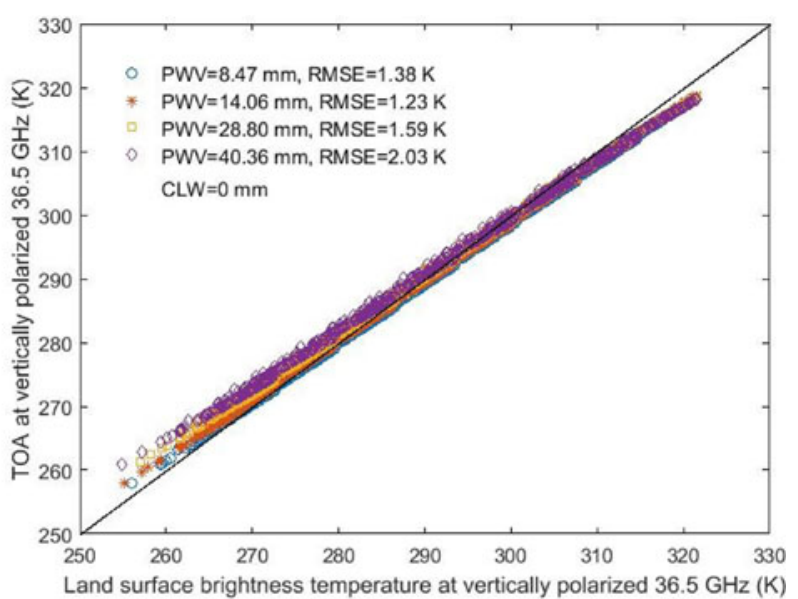

(c)

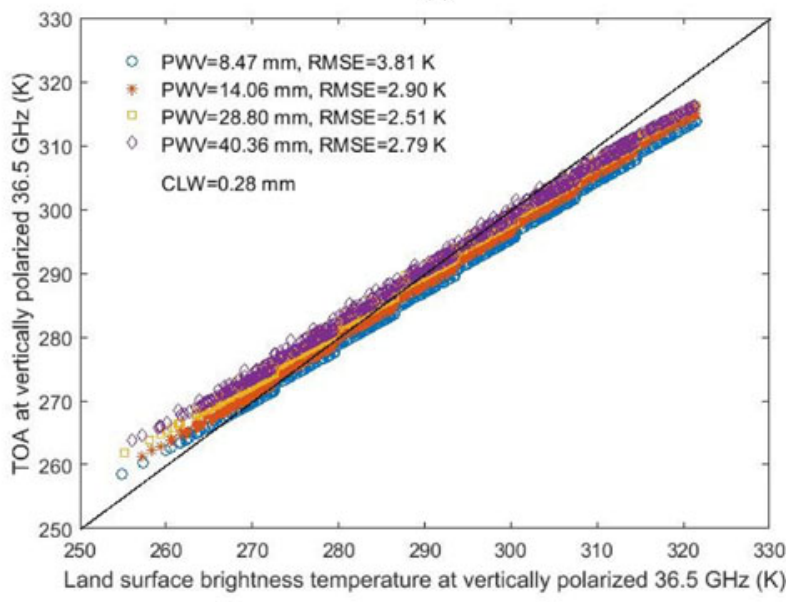

(d)

Fig. 1. Atmospheric effects on 18.7 and $36.5 \mathrm{GHz}$ : (a) atmospheric effect on $18.7 \mathrm{GHz}$ without CLW; (b) atmospheric effect on $18.7 \mathrm{GHz}$ with CLW; (c) atmospheric effect on $36.5 \mathrm{GHz}$ without CLW; (d) atmospheric effect on $36.5 \mathrm{GHz}$ with CLW.

Although the algorithm of Gao et al. is practical, it is limited in some areas. At the same land surface conditions, horizontally polarized emissivities are smaller than vertically polarized ones, and the differences are much more obvious, especially on the arid and semi-bare soils, as well as surfaces that have some fractional water contribution. The horizontally polarized reflectivities are larger in these places, which means that the atmospheric effect is greater and maybe the cause of some errors if it is directly ignored [50]. In contrast, the vertically polarized emissivities are closer to unity for most of the land cover types. Hence, the vertically polarized brightness temperature data are more insensitive to the atmospheric effect and suitable for the simple LST retrieval algorithm [see (1), here $p$ stands for vertical polarization). This leads us to believe that using vertically polarized emissivities instead of horizontally polarized ones is important to retrieve the LST. Fig. 2 shows the relationships between the PR at $18.7 \mathrm{GHz}$ and vertically polarized emissivities with the simulated data. As seen in Fig. 2, whether bare soil or vegetation, there are no obvious parameterized relationships between PR and vertically polarized emissivities. The points are roughly divided into two parts: the sparse part, which appears rectangular on the left side and the dense part, which appears

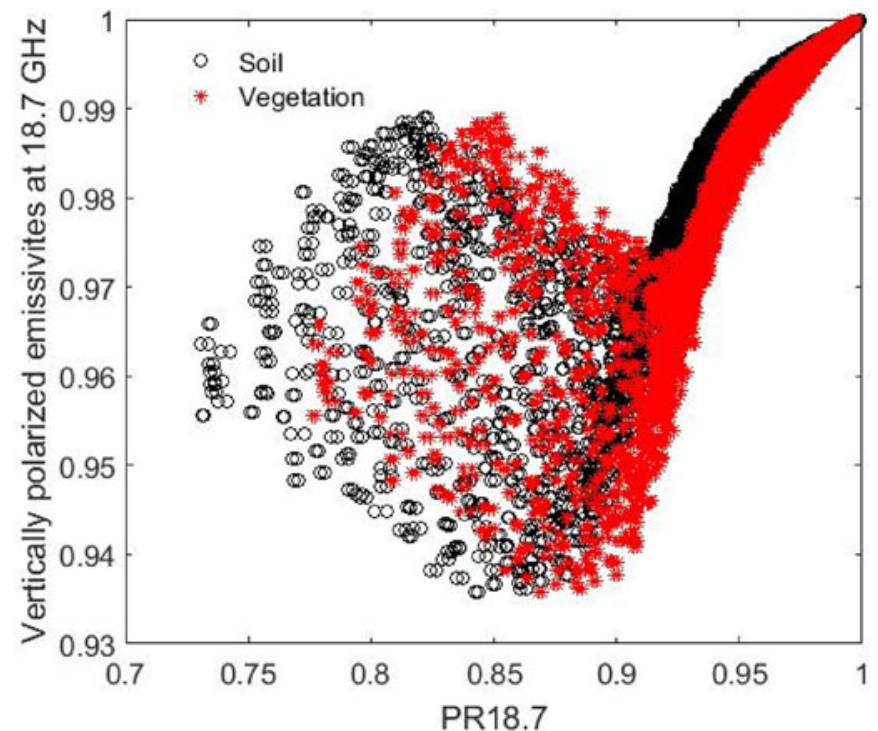

Fig. 2. Relationships between the PR at $18.7 \mathrm{GHz}$ and vertically polarized emissivities with the simulated data. 


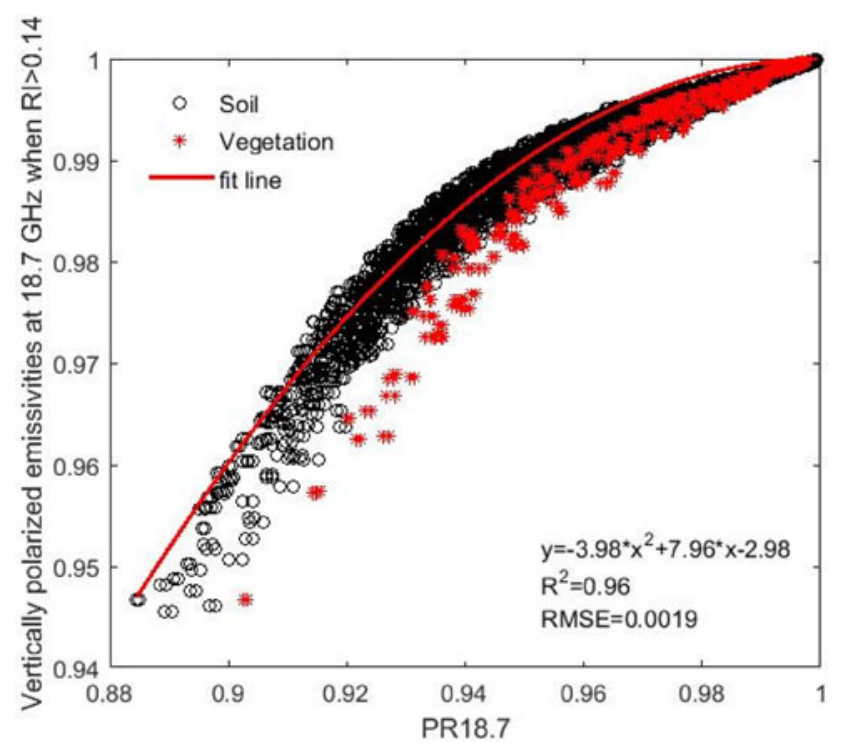

Fig. 3. Relationship between the PR at $18.7 \mathrm{GHz}$ and the vertically polarized emissivities when RI $>0.14$.

quadratic on the right side. Consequently, if the left part could be legitimately ignored, the vertically polarized emissivities can be estimated from the PR. The point is to figure out how to legitimately ignore the left rectangular part. This question includes two aspects: where is the demarcation point that divides the left and right parts, and why can the left part be ignored?

To answer these two questions, the simulated data are analyzed. Under the same frequency, polarization, and incidence angle conditions, the emissivities are mainly influenced by the soil moisture content and surface roughness [51]. To quantitatively describe the surface roughness conditions, a roughness index (RI, defined as the ratio of RMS height to cl) is used in this study and the rougher the land surface, the larger the RI. By analyzing Fig. 2, the relationships between the PR at $18.7 \mathrm{GHz}$ and the vertically polarized emissivities can be described as quadratic with almost the same curvature from left to right with increasing RI when RI $<0.14$; when RI $>0.14$, the scatters are assembled in the right portion. In other words, the left rectangular part represents the smoother surfaces. The entire range of simulated RI is from 0.019 to 1.12 . As mentioned earlier, the RMS height and cl reference the data from seven artificial plots, from "a rough freshly plowed field" to "a plot which was artificially crushed and compressed by a road roller to obtain a surface as smooth as possible." Consequently, the smoothest surface is ideal and does not exist. There must be a transition zone from the ideal plane to real, rough land surfaces. In the left part, $\mathrm{RI}<0.14$ is assumed to represent the transition zone.

Ignoring the left part, the relationship between the PR and vertically polarized emissivities at $18.7 \mathrm{GHz}$ can be expressed as a quadratic function [see (2)], with an $R^{2}$ of 0.96 and RMSE of 0.0019 (see Fig. 3):

$$
e_{18, v}=-3.98 \times \mathrm{PR}_{18}^{2}+7.96 \times \mathrm{PR}_{18}-2.98
$$

where $\mathrm{PR}_{18}$ is the $\mathrm{PR}$ at $18.7 \mathrm{GHz}$ and $e_{18, v}$ is the vertically polarized emissivity at $18.7 \mathrm{GHz}$. As seen in Fig. 3, the vertically polarized emissivities increase with the increasing PR but the

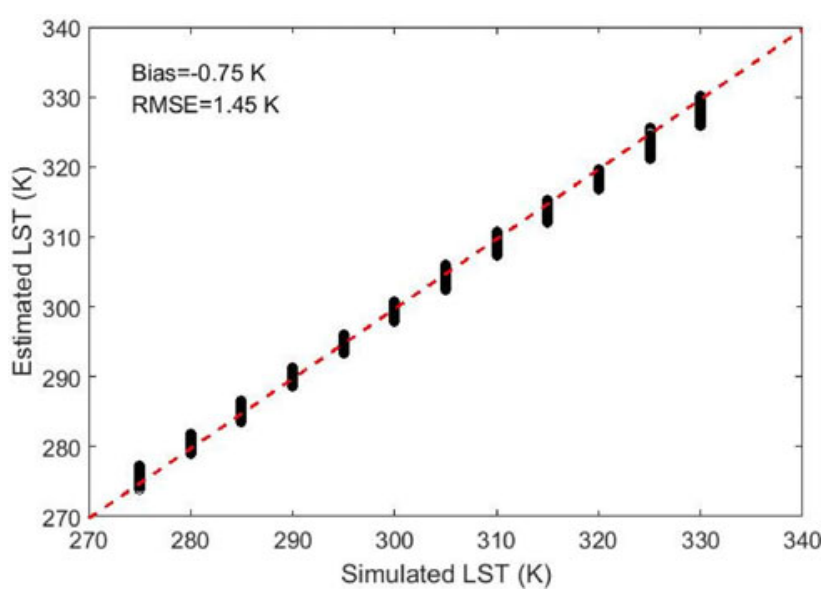

Fig. 4. Comparison of the estimated LST and given LST in the simulation.

speed gradually slows. The distribution trends of the scatters for both soil and vegetation are similar. This means the relationship between PR and vertically polarized emissivities is adaptable for both soil and vegetation. In addition, the LST can be measured with the estimated emissivities. Fig. 4 depicts the comparison of the estimated LST from this retrieval algorithm and the given LST in the simulation. A bias of $-0.75 \mathrm{~K}$ and RMSE of $1.45 \mathrm{~K}$ exist when the total LST range is $55 \mathrm{~K}$, which proves that this retrieval algorithm can estimate not only the vertically polarized emissivities but also the LST with very high accuracies when using just the brightness temperature observations at $18.7 \mathrm{GHz}$.

\section{RI Estimation Algorithm}

In practical applications, it is necessary to first screen out the regions where the LST retrieval algorithm is not applicable $(\mathrm{RI}<0.14)$ to ensure the physical rationality of the algorithm. However, the two roughness parameters (sig and cl) are scaledependent and no reliable products exist at passive microwave remotely sensed pixel scales. To overcome the problem, a simple RI parameterized model based on the simulated data is developed [see (3)]. Through the differences in the vertically and horizontally polarized emissivities at $18.7 \mathrm{GHz}$, RI can be estimated with an $R^{2}$ of 0.84 and RMSE of 0.026 (see Fig. 5). In addition, the areas where RI $<0.14$ will be removed. As seen in Fig. 5, there is a bias of -0.002 , which means that the real RI $>0.14$ of some study areas may be underestimated. Although it may lead to some study areas being wrongly removed by the retrieval algorithm, it ensures the model accuracy

$$
\mathrm{RI}=0.0033 \times\left(e_{18, v}-e_{18, h}\right)^{-1.495}
$$

where $e_{18, v}$ and $e_{18, h}$ are vertically and horizontally polarized emissivities at $18.7 \mathrm{GHz}$, respectively.

\section{RESUlTS AND DISCUSSIONS}

\section{A. Sensitivity of the LST Retrieval Algorithm to Errors of Brightness Temperature Observations}

Because the LST retrieval algorithm is based on the estimation of LSE, which is only related to the vertically and horizontally polarized brightness temperature observations at $18.7 \mathrm{GHz}$, 


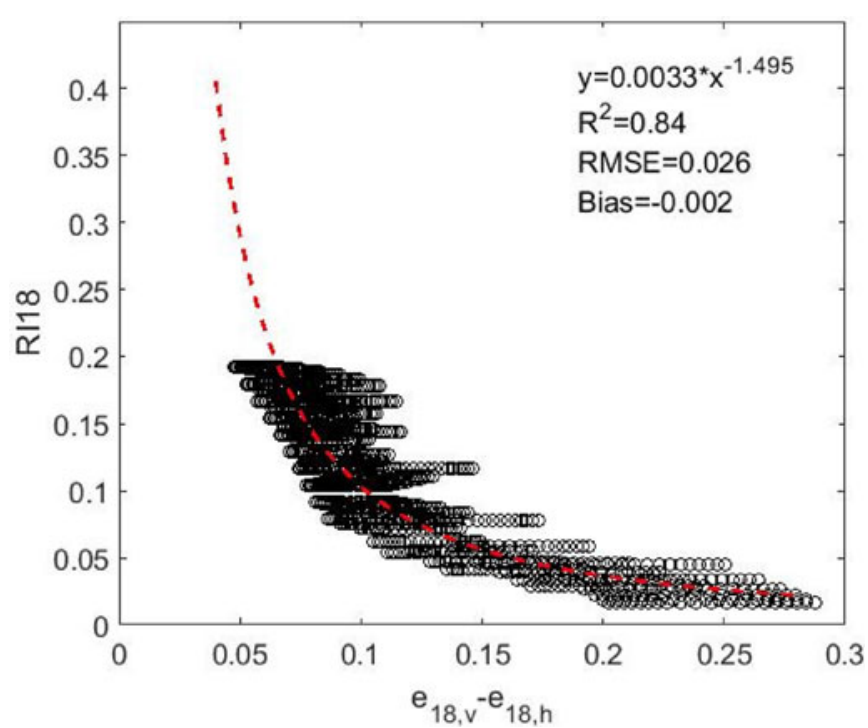

Fig. 5. Relationship between the differences in the vertically and horizontally polarized emissivities at $18.7 \mathrm{GHz}$ and RI.

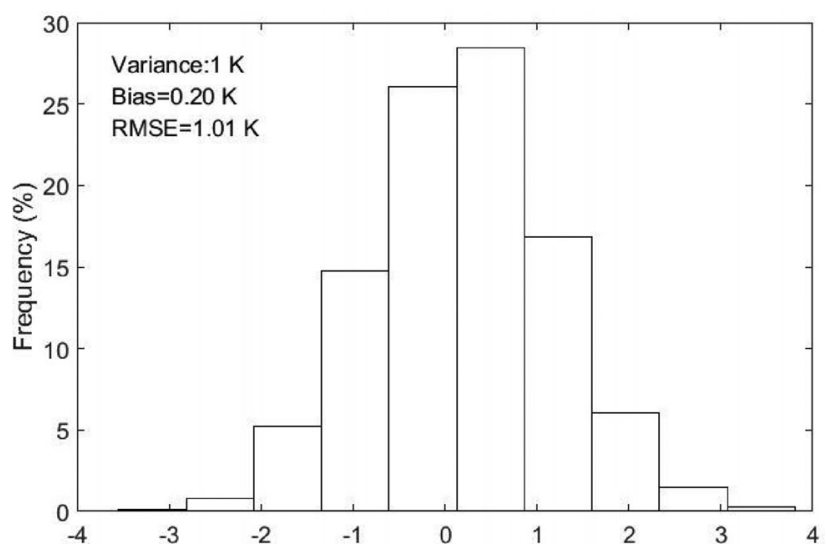

Fig. 6. Histograms of differences in the retrieved LST with and without the brightness temperature errors.

the data quality of the brightness temperature observations will inevitably affect the retrieval accuracy. It is necessary to assess the sensitivity of the LST retrieval algorithm for errors in the brightness temperature observations. Du et al. [52] found that there was 0-5 K mean biases among Feng Yun-3, AMSR-E and AMSR2 brightness temperature observations at $18.7 \mathrm{GHz}$ with horizontal polarization. Cavalieri et al. [53] proved that the F13 and F17 brightness temperature observations at $37 \mathrm{GHz}$ of $\mathrm{SSM} / \mathrm{I}$ presented a bias of $1 \mathrm{~K}$ over the summer of 2007 over the circumpolar Northern Hemisphere. In this study, two series of normally distributed brightness temperature errors of $1 \mathrm{~K}$, $\operatorname{error}_{T B 18, v} \sim N\left(0,1^{2}\right)$ and $\operatorname{error}_{T B 18, h} \sim N\left(0,1^{2}\right)$ are added to the originally simulated data, respectively. Fig. 6 shows the histograms of differences in the retrieved LST with and without the brightness temperature errors. A variance of $1 \mathrm{~K}$ will cause a bias of $0.2 \mathrm{~K}$ and an RMSE of $1.01 \mathrm{~K}$ compared with no brightness temperature errors, and 90 percent of the total differences are less than $2 \mathrm{~K}$, which means that the retrieval algorithm is not sensitive to errors in the brightness temperature observations.

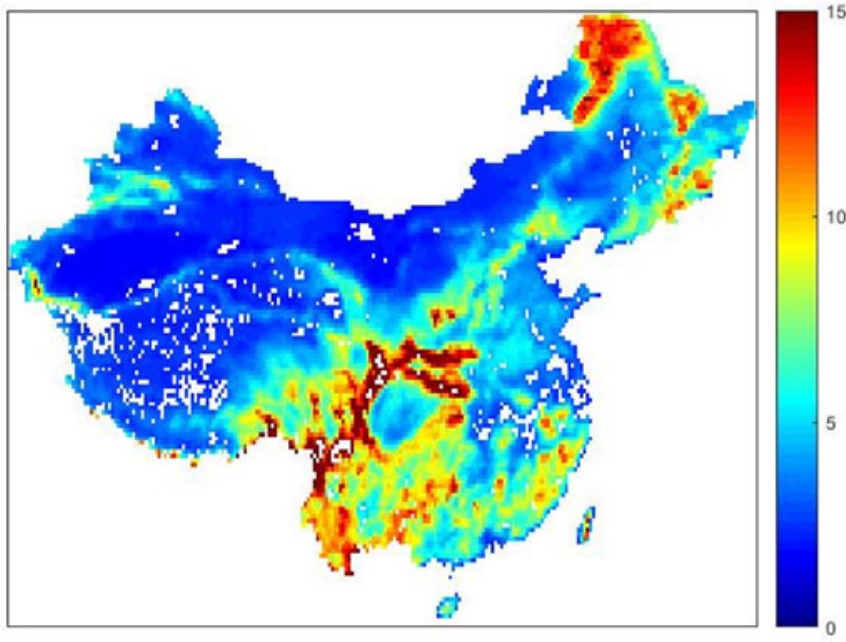

Fig. 7. Year-round RI of the Chinese mainland.

\section{B. Evaluation of the Study Area}

At first, we should evaluate the study area, choosing the areas that are suitable for the LST retrieval algorithm (in other words, RI > 0.14). The entire 12-month AMSR-E monthly microwave LSE products at $18.7 \mathrm{GHz}$ with vertical and horizontal polarization from 2007 over the Chinese mainland are used to calculate the RI. In this study, 52 pixels with RI values of less than 0.14 in any month are excluded, which only covers $0.3 \%$ of the total study area. In addition, the marked snow, ice and water pixels using the MCD12 in 2007 are also excluded, which covers $4.8 \%$ of the total study area. The chosen study area is shown in Fig. 7. The value of each pixel is the sum of the RI for one year. The larger the value is, the rougher the land surface is. As seen in Fig. 7, the lower RI values are mainly located in the bare soil and sparse vegetation areas and the higher values are mainly in the mixed forests and evergreen broadleaf forest regions.

\section{Validation by the Monthly AMSR-E LSE Product}

Because of the absence of the daily AMSR-E LSE product, the monthly AMSR-E LSE product from Jul. 2007 is used to validate the accuracy of the estimated LSE (see Fig. 8). As seen in Fig. 8, the distribution trend of the estimated LSE is similar to the AMSR-E product, and the RMSE is 0.014 (not shown). The larger LSE values are mostly located in the western Yunnan and Sichuan Provinces and in the desert areas of the Xinjiang and Inner Mongolia Provinces. The lower LSE values are mostly located in the lower reaches of the Yangtze River and coastlines. In South China where there are often clouds in the summers, the estimated LSE distribution is similar to the AMSR-E product, which means that our algorithm has a high accuracy in cloudy areas. However, the obvious differences are seen in arid and semiarid regions, in which overestimations exist compared to the AMSR-E product.

\section{Validation by the Daily MODIS LST Product}

The MODIS LST products from June, July and August 2007 are used to evaluate the accuracy of the LST retrieval 


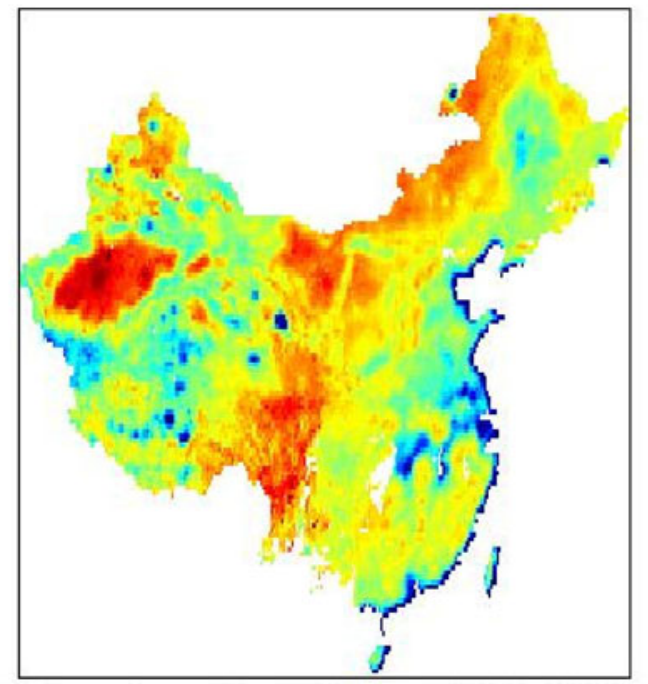

Estimated monthly AMSR-E LSE in Jul. 2007
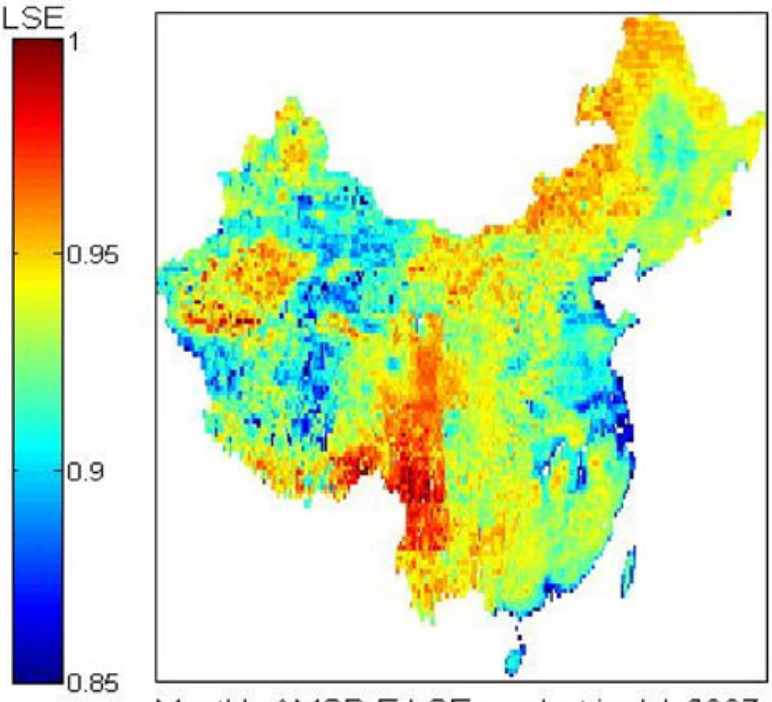

Monthly AMSR-E LSE product in Jul. 2007

Fig. 8. Comparison between the monthly estimated LSE and monthly AMSR-E product in July 2007.

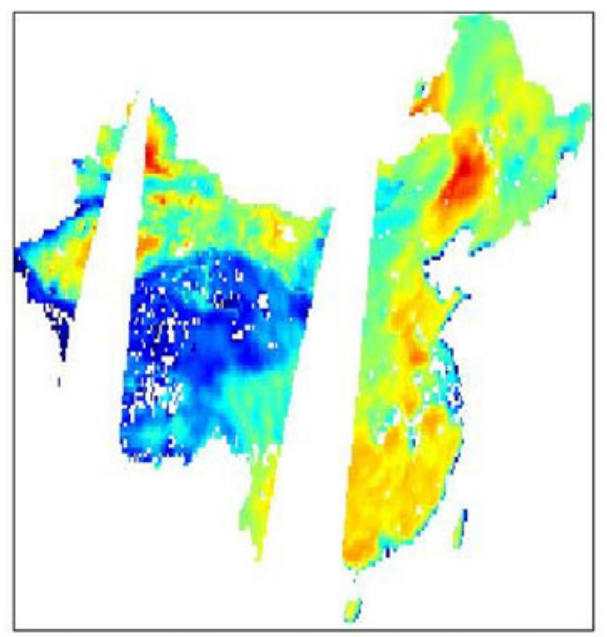

Estimated LST from AMSR-E in Jun. 182007

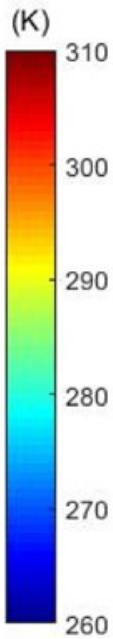

Simultaneous MODIS LST product in Jun. 182007

Fig. 9. Comparison between the estimated LST from the AMSR-E brightness temperature observations and the simultaneous MODIS LST product from June $18,2007$.

algorithm. The data from Jun. 15 are used to calibrate the coefficients of (2) in isolation. Fig. 9 shows the comparison between the estimated LST from the AMSR-E brightness temperature observations and the simultaneous MODIS LST product from Jun. 18, 2007. When the AMSR-E LST observations are paired with the MODIS LST products, the bias and RMSE are 0.24 and $3.04 \mathrm{~K}$, respectively. The result is acceptable. As seen in Fig. 9, the more notable differences between the two observations are in desert areas, the Gurbantunggut and Taklimakan Deserts, where the AMSR-E LST are obviously greater than the MODIS LST. Due to the existence of the vast and frequent clouds during the Northern Hemisphere summer, the MODIS LST product has a mass of null data in the central and eastern parts of the Chinese mainland. However, the passive microwave remotely sensed observations at $18.7 \mathrm{GHz}$ have the advantage of penetrating clouds and obtaining ground information. This helps us to map the LST distribution under all weather conditions. Unfortunately, because the swath width of the AMSR-E is $1450 \mathrm{~km}$, it is relatively narrower than that of the MODIS, which is $2330 \mathrm{~km}$. That is the reason there are two gaps with no valid observations in the left figure. In consideration of the monthly AMSR-E and MODIS observations having a greater possibility to cover the entire study areas, comparison with the monthly MODIS LST product is necessary for a better evaluation of the LST retrieval algorithm.

\section{E. Validation Using the Monthly MODIS LST Product}

Fig. 10 shows the comparison between the bimonthly AMSRE LST and the simultaneous MODIS LST products in July and August 2007, in which the bias and RMSE are -0.37 and $4.43 \mathrm{~K}$, respectively. As seen in Fig. 10, just like the daily validation, the 


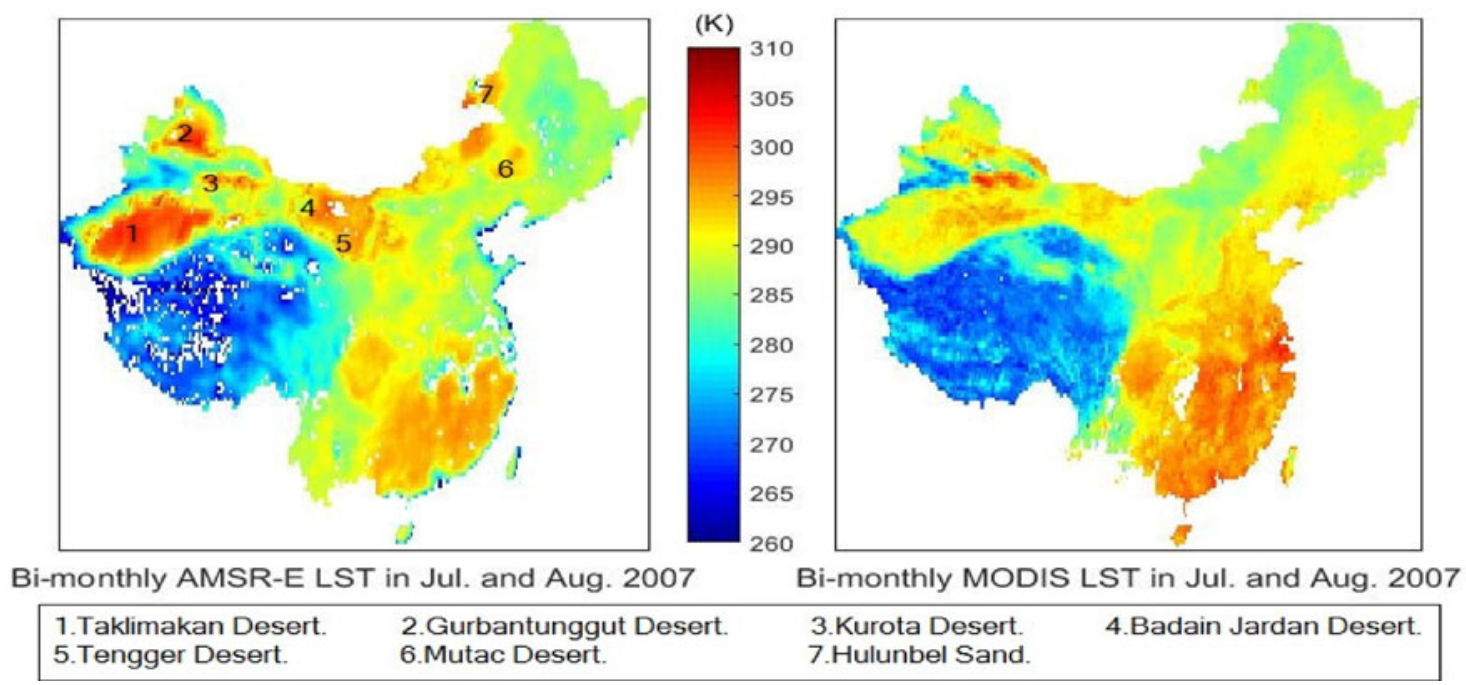

Fig. 10. Comparison between the bimonthly AMSR-E LST and the simultaneous MODIS LST products in July and August 2007.

AMSR-E LST are obvious greater than the MODIS LST in the desert areas, which includes the Taklimakan Desert, the Gurbantunggut Desert, the Kurota Desert, the Badain Jaran Desert, the Tengger Desert, the Mutac Desert, and the Hulunbel Sand, and these are all marked in the figure from 1 to 7 . This may be the result of two reasons: 1) comparisons between the in situ LST and MODIS LST over arid and semiarid regions have reported that MODIS products significantly underestimate the LST [9], [10], [15], [54]-[56]; 2) due to a larger wavelength, microwave radiation may emanate from the deep soil layers below the surface skin, and the temperature information detected by the passive microwave radiation is not from the land surface but the subsurface. Hence, the temperature is a comprehensive reflection of the layers below the surface. This effect is particularly relevant over arid and semiarid regions, where the penetrating power of the passive microwave radiation is stronger because of the lack of water. On summer nights, the temperatures of the deeper desert are usually higher than the surface temperatures. Consequently, the comprehensive temperatures (AMSR-E LST) are higher than the surface temperatures (MODIS LST). Contrary to the overestimations in the arid and semiarid regions, we find that there are obvious underestimations in the southeastern Chinese mainland. A possible explanation is that these parts only have infrared LST values on clear-sky days, which are higher than those days under the vast and frequent clouds. However, the bimonthly AMSR-E LST values are derived from all weather conditions and are averaged down by these cloudy LST values. As a result, the AMSR-E LST in the southeastern Chinese mainland look more reasonable compared to the MODIS LST.

\section{F. Validation by the In Situ LST Observations}

It is difficult to validate the estimated AMSR-E LST by in situ observations because the spatial resolutions of the two datasets are completely different. The former is $25 \mathrm{~km} \times 25 \mathrm{~km}$, and the latter is at a point scale. In this study, 728 in situ observations from meteorological stations on Jul. 3, 2007 are used to just

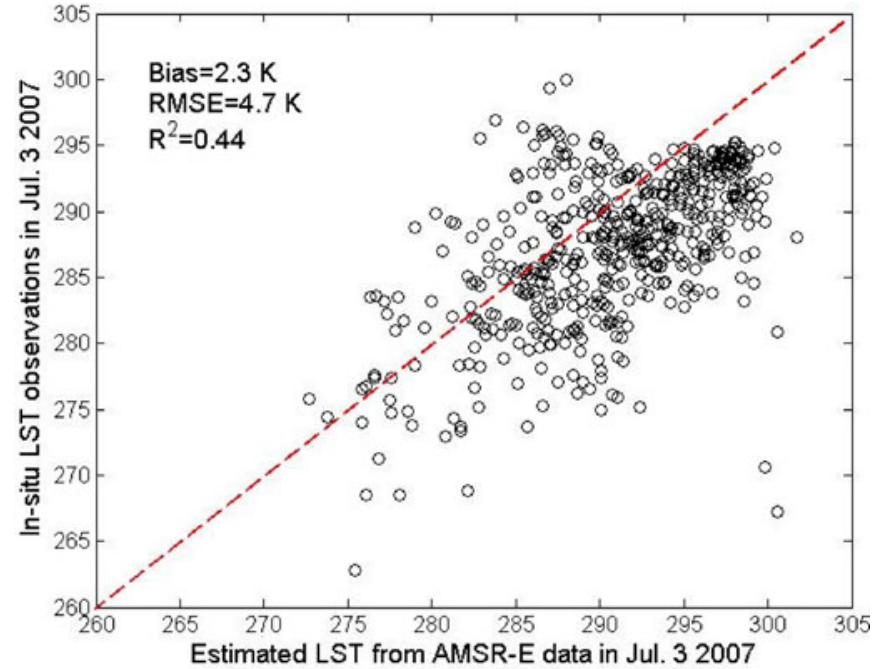

Fig. 11. Relationship between the estimated AMSR-E LST and the in situ LST observations on July 3, 2007.

show the relationship between the estimated AMSR-E LST and the in situ LST observations (see Fig. 11). As seen in Fig. 11, in the temperature range of approximately $30 \mathrm{~K}(270-300 \mathrm{~K})$, points are dispersed on both sides of the 1:1 line with an RMSE of $4.7 \mathrm{~K}$ and $R^{2}$ of 0.44 . An overestimation of $2.3 \mathrm{~K}$ exists and may be caused by the difference in spatial resolutions or the change in LST from 0130 to 0200.

\section{CONCLUSION}

A practical two-stage algorithm for retrieving the LST from the AMSR-E brightness temperature observations at $18.7 \mathrm{GHz}$ is proposed in this study. First, a parameterization relationship between the PR and LSE is developed to estimate the vertically polarized LSE at $18.7 \mathrm{GHz}$. Second, the estimated LSE is used to retrieve the LST by ignoring the atmospheric effect. This LST retrieval algorithm has three advantages: 1) it can obtain the LSE estimations; 2) it is suitable for all weather conditions 
because it uses the lower frequency; and 3) it applies to the most land cover types except for snow, ice and water. The validation with the simulated data shows an RMSE of $1.45 \mathrm{~K}$, which is very encouraging. The validations with the satellite products are at daily and monthly time scales. The result reveals that the daily accuracy is $3.04 \mathrm{~K}$. Although the AMSR-E LST regions, which have valid data, are larger than those of MODIS because of the penetrating power of the clouds, there are always gaps in the Chinese mainland due to the relatively narrow swath width. To evaluate the LST retrieval algorithm with more valid data, we compare the bimonthly AMSR-E LST and the simultaneous MODIS LST products for Jul. and Aug. 2007. A high positive bias in the arid and semiarid regions and a negative bias in the frequently cloudy regions are noticeable. These biases do not reveal the uncertainties of this LST retrieval algorithm. Conversely, the AMSR-E LST look more reasonable compared with the MODIS LST under certain circumstances.

The improvements for this LST retrieval algorithm are addressed in ongoing work and two main aspects are concluded: 1) further evaluations of LSE and LST in arid and semiarid regions, as well as in frequently cloudy areas are needed; and 2 ) the retrieval of the LST is important in the excluded areas in this study, which includes the areas of RI $<0.14$ and the masked snow, ice and water areas.

\section{REFERENCES}

[1] M. C. Anderson, J. M. Norman, W. P. Kustas, R. Houborg, P. J. Starks, and N. Agam, "A thermal-based remote sensing technique for routine mapping of land-surface carbon, water and energy fluxes from field to regional scales," Remote Sens. Environ., vol. 112, pp. 4227-4241, Dec. 2008.

[2] Z.-L. Li et al., "Satellite-derived land surface temperature: Current status and perspectives," Remote Sens. Environ., vol. 131, pp. 14-37, Apr. 2013.

[3] C. P. McKay and E. I. Friedmann, "The cryptoendolithic microbial environment in the Antarctic cold desert: Temperature variations in nature," Polar Biol., vol. 4, pp. 19-25, 1985.

[4] S. K. Alavipanah et al., "Remote sensing application in evaluation of soil characteristics in desert areas," Nat. Environ. Change, vol. 2, pp. 1-24, 2016.

[5] W. P. Kustas and J. M. Norman, "Use of remote sensing for evapotranspiration monitoring over land surfaces," Hydrol. Sci. J., vol. 41, pp. 495-516, 1996.

[6] G. Wohlfahrt, L. F. Fenstermaker, and J. A. Arnone, III, "Large annual net ecosystem $\mathrm{CO}_{2}$ uptake of a Mojave desert ecosystem," Global Change Biol., vol. 14, pp. 1475-1487, 2008.

[7] M. J. McFarland, R. L. Miller, and C. M. Neale, "Land surface temperature derived from the SSM/I passive microwave brightness temperatures," IEEE Trans. Geosci. Remote, vol. 28, no. 5, pp. 839-845, Sep. 1990.

[8] J. R. G. Townshend et al., "The $1 \mathrm{~km}$ resolution global data set: Needs of the International geosphere biosphere programme," Int. J. Remote Sens., vol. 15, pp. 3417-3441, 1994.

[9] S. L. Ermida, I. F. Trigo, C. C. DaCamara, F. M. Göttsche, F. S. Olesen, and G. Hulley, "Validation of remotely sensed surface temperature over an oak woodland landscape-The problem of viewing and illumination geometries," Remote Sens. Environ., vol. 148, pp. 16-27, 2014.

[10] F. M. Göttsche, F. S. Olesen, I. F. Trigo, A. Bork-Unkelbach, and M. A. Martin, "Long term validation of land surface temperature retrieved from MSG/SEVIRI with continuous in-situ measurements in Africa," Remote Sens., vol. 8, p. 410, May 2016.

[11] J. A. Augustine, G. B. Hodges, C. R. Cornwall, J. J. Michalsky, and C. I. Medina, "An update on SURFRAD—The GCOS surface radiation budget network for the continental United States," J. Atmos. Ocean Tech., vol. 22, pp. 1460-1472, 2005.

[12] G. M. Stokes and S. E. Schwartz, "The atmospheric radiation measurement (ARM) program: Programmatic background and design of the cloud and radiation test bed," Bull. Amer. Meteorol. Soc., vol. 75, pp. 1201-1221, 1994.
[13] T. Koike, "The coordinated enhanced observing period-an initial step for integrated global water cycle observation," WMO Bull., vol. 53, pp. 115-121, 2004.

[14] H. Gao, R. Fu, R. E. Dickinson, and R. I. N. Juarez, "A practical method for retrieving land surface temperature from AMSR-E over the Amazon forest," IEEE Trans. Geosci. Remote, vol. 46, no. 1, pp. 193-199, Jan. 2008.

[15] H. Li et al., "Evaluation of the VIIRS and MODIS LST products in an arid area of Northwest China," Remote Sens. Environ., vol. 142, pp. 111-121, 2014.

[16] L. Li, E. G. Njoku, E. Im, P. S. Chang, and K. S. Germain, "A preliminary survey of radio-frequency interference over the US in Aqua AMSR-E data," IEEE Trans. Geosci. Remote, vol. 42, no. 2, pp. 380-390, Feb. 2004.

[17] Z.-L. Li and F. Becker, "Feasibility of land surface temperature and emissivity determination from AVHRR data," Remote Sens. Environ., vol. 43 pp. 67-85, 1993 .

[18] Z.-L. Li et al., "Experimental system for the study of the directional thermal emission of natural surfaces," Int. J. Remote Sens., vol. 25 , pp. 195-204, 2004.

[19] J. A. Sobrino and J. C. Jiménez-Muñoz, "Land surface temperature retrieval from thermal infrared data: An assessment in the context of the surface processes and ecosystem changes through response analysis (SPECTRA) mission," J. Geophys. Res.: Atmospheres, vol. 110, no. D16, 2005, Art. no. D16103.

[20] J. A. Sobrino, J. C. Jiménez-Muñoz, L. Balick, A. R. Gillespie, D. A Sabol, and W. T. Gustafson, "Accuracy of ASTER level-2 thermal-infrared standard products of an agricultural area in Spain," Remote Sens. Environ., vol. 106, pp.146-153, 2007.

[21] C. Jiménez, C. Prigent, S. L. Ermida, and J. L. Moncet, "Inversion of AMSR-E observations for land surface temperature estimation: 1 Methodology and evaluation with station temperature," J. Geophys. Res.: Atmospheres, vol. 122, pp. 3330-3347, 2017.

[22] C. J. Hahn, S. G. Warren, and J. London, "The effect of moonlight on observation of cloud cover at night, and application to cloud climatology," J. Climate, vol. 8, pp. 1429-1446, 1995.

[23] C. Prigent and W. R. Rossow, "Retrieval of surface and atmospheric parameters over land from SSM/I: Potential and limitations," $Q$. J. Roy. Meteor. Soc., vol. 125, pp. 2379-2400, 1999.

[24] C. Prigent, P. Liang, Y. Tian, F. Aires, J. L. Moncet, and S. A. Boukabara, "Evaluation of modeled microwave land surface emissivities with satellitebased estimates," J. Geophys. Res.: Atmospheres, vol. 120, pp. 2706-2718, 2015.

[25] C. Prigent, W. B. Rossow, and E. Matthews, "Microwave land surface emissivities estimated from SSM/I observations," J. Geophys. Res.: At mospheres, vol. 102, pp. 21867-21890, 1997.

[26] C. Prigent, F. Aires, and W. B. Rossow, "Land surface microwave emissivities over the globe for a decade," Bull. Amer. Meteorol. Soc., vol. 87 pp. 1573-1584, 2006.

[27] J. L. Moncet et al., "Land surface microwave emissivities derived from AMSR-E and MODIS measurements with advanced quality control," $J$ Geophys. Res.: Atmospheres, vol. 116, 2011.

[28] H. Norouzi, M. Temimi, W. B. Rossow, C. Pearl, and R. Khanbilvardi, "The sensitivity of land emissivity estimates from AMSR-E at C and X bands to surface properties," Hydrol. Earth Syst. Sci., vol. 15, p. 3577, 2011.

[29] F. Karbou, C. Prigent, L. Eymard, and J. R. Pardo, "Microwave land emissivity calculations using AMSU measurements," IEEE Trans. Geosci. Remote, vol. 43, no. 5, pp. 948-959, May 2005.

[30] F. A. Furuzawa, H. Masunaga, and K. Nakamura, "Development of a land surface emissivity algorithm for use by microwave rain retrieval algorithms," in Proc. SPIE Asia-Pacific Remote Sens., 2012, pp. $85231 \mathrm{~W}-85231 \mathrm{~W}$.

[31] F. J. Turk, L. Li, and Z. S. Haddad, "A physically based soil moisture and microwave emissivity data set for Global Precipitation Measurement (GPM) applications," IEEE Trans. Geosci. Remote, vol. 52, no. 12 , pp. 7637-7650, Dec. 2014.

[32] S. Prakash, H. Norouzi, M. Azarderakhsh, R. Blake, and K. Tesfagiorgis, "Global land surface emissivity estimation from AMSR2 observations," IEEE Geosci. Remote Sens. Lett., vol. 13, no. 9, pp. 1270-1274, Sep. 2016.

[33] F. Karbou, F. Rabier, and C. Prigent, "The assimilation of observations from the advanced microwave sounding unit over sea ice in the French global numerical weather prediction system," Mon. Weather Rev., vol. 142, pp. 125-140, 2014.

[34] H. Norouzi et al., "Assessment of the consistency among global microwave land surface emissivity products," Atmos. Meas. Tech., vol. 8, p. 1197 , 2015. 
[35] J. R. Wang and T. J. Schmugge, "An empirical model for the complex dielectric permittivity of soils as a function of water content," IEEE Trans. Geosci. Remote, vol. 4, no. 4, pp. 288-295, Oct. 1980.

[36] B. J. Choudhury, T. J. Schmugge, A. Chang, and R. W. Newton, "Effect of surface roughness on the microwave emission from soils," J. Geophys. Res.: Oceans, vol. 84, pp. 5699-5706, 1979.

[37] J. R. Wang and B. J. Choudhury, "Remote sensing of soil moisture content, over bare field at $1.4 \mathrm{GHz}$ frequency," J. Geophys. Res.: Oceans, vol. 86, pp. 5277-5282, 1981.

[38] J. P. Wigneron, L. Laguerre, and Y. H. Kerr, "A simple parameterization of the L-band microwave emission from rough agricultural soils," IEEE Trans. Geosci. Remote, vol. 39, no. 8, pp. 1697-1707, Aug. 2001.

[39] K. S. Chen, T. D. Wu, L. Tsang, Q. Li, J. Shi, and A. K. Fung, "Emission of rough surfaces calculated by the integral equation method with comparison to three-dimensional moment method simulations," IEEE Trans. Geosci. Remote, vol. 41, no. 1, pp. 90-101, Jan. 2003.

[40] J. Shi, L. Jiang, L. Zhang, K. S. Chen, J. P. Wigneron, and A. Chanzy, "A parameterized multifrequency-polarization surface emission model," IEEE Trans. Geosci. Remote, vol. 43, no. 12, pp. 2831-2841, Dec. 2005.

[41] L. Chen, J. Shi, J. P. Wigneron, and K. S. Chen, "A parameterized surface emission model at L-band for soil moisture retrieval," IEEE Geosci. Remote Sens. Lett., vol. 7, no. 1, pp. 127-130, Jan. 2010.

[42] F. T. Ulaby, R. K. Moore, and A. K. Fung, "RADIOMETRY," in $M i-$ crowave Remote Sensing: Active and Passive, vol. 1, 3rd ed. Reading, MA, USA: Addison-Wesley, 1981, pp. 186-255.

[43] Z. Wan, Y. Zhang, Q. Zhang, and Z.-L. Li, "Validation of the land-surface temperature products retrieved from Terra Moderate Resolution Imaging Spectroradiometer data," Remote Sens. Environ., vol. 83, pp. 163-180, 2002.

[44] Z. Wan, Y. Zhang, Q. Zhang, and Z.-L. Li, "Quality assessment and validation of the MODIS global land surface temperature," Int. J. Remote Sens., vol. 25, pp. 261-274, 2004.

[45] Z. Wan and Z.-L. Li, "A physics-based algorithm for retrieving landsurface emissivity and temperature from EOS/MODIS data," IEEE Trans. Geosci. Remote, vol. 35, no. 4, pp. 980-996, Jul. 1997.

[46] C. Prigent, F. Aires, and W. B. Rossow, "Retrieval of surface and atmospheric geophysical variables over snow-covered land from combined microwave and infrared satellite observations," J. Appl. Meteorol. Clim. vol. 42, pp. 368-380, 2003.

[47] E. Cordisco, C. Prigent, and F. Aires, "Snow characterization at a global scale with passive microwave satellite observations," J. Geophys. Res. Atmospheres, vol. 111, 2006, Art. no. D19102.

[48] M. Owe and A. A. Van De Griend, "On the relationship between thermodynamic surface temperature and high-frequency $(37 \mathrm{GHz})$ vertically polarized brightness temperature under semi-arid conditions," Int. $J$. Remote Sens., vol. 22, pp. 3521-3532, 2001.

[49] M. Fily, A. Royer, K. Goita, and C. Prigent, "A simple retrieval method for land surface temperature and fraction of water surface determination from satellite microwave brightness temperatures in sub-arctic areas," Remote Sens. Environ., vol. 85, pp. 328-338, 2003.

[50] F.-C. Zhou, X. Song, P. Leng, H. Wu, and B.-H. Tang, "An algorithm for retrieving precipitable water vapor over land based on passive microwave satellite data," Adv. Meteorol., vol. 2016, pp. 1-11, 2016.

[51] T. J. Hewison, "Airborne measurements of forest and agricultural land surface emissivity at millimeter wavelengths," IEEE Trans. Geosci. Remote, vol. 39, no. 2, pp. 393-400, Feb. 2001.

[52] J. Du et al., "Inter-calibration of satellite passive microwave land observations from AMSR-E and AMSR2 using overlapping FY3B-MWRI sensor measurements," Remote Sens., vol. 6, pp. 8594-8616, 2014.

[53] D. J. Cavalieri, C. L. Parkinson, N. DiGirolamo, and A. Ivanoff, "Intersensor calibration between F13 SSMI and F17 SSMIS for global sea ice data records," IEEE Geosci. Remote Sens. Lett., vol. 9, no. 2, pp. 233-236, Mar. 2012.

[54] C. O. Justice et al., "Land and cryosphere products from Suomi NPP VIIRS: Overview and status," J. Geophys. Res.: Atmospheres, vol. 118, pp. 9753-9765, 2013.

[55] P. C. Guillevic et al., "Validation of land surface temperature products derived from the visible infrared imaging radiometer suite (VIIRS) using ground-based and heritage satellite measurements," Remote Sens. Environ., vol. 154, pp. 19-37, 2014

[56] I. F. Trigo, I. T. Monteiro, F. Olesen, and E. Kabsch, "An assessment of remotely sensed land surface temperature," J. Geophys. Res.: Atmospheres, vol. 113, pp. 1161-1165, 2008.

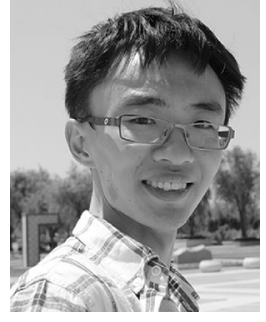

Fang-Cheng Zhou received the B.E. degree from the China University of Mining and Technology, Xuzhou, China, in 2011, and the M.S. degree from the University of Chinese Academy of Sciences, Beijing, China, in 2014. He is currently working toward the $\mathrm{Ph} . \mathrm{D}$. degree at the Institute of Geographic Sciences and Natural Resources Research, Chinese Academy of Sciences, Beijing.

His current research interests include passive microwave remote sensing and retrieval of land surface and atmospheric parameters from satellite data.

Zhao-Liang Li received the Ph.D. degree from the University of Strasbourg, Strasbourg, France, in 1990.

Since 1992, he has been a Research Scientist with ICube, Illkirch, France. He joined the Institute of Agricultural Resources and Regional Planning, Beijing, China, in 2012. He has participated in many national and international projects such as the National Aeronautics and Space Administration (NASA)-funded Moderate Resolution Imaging Spectroradiometer, the European Community (EC)-funded program Exploitation of angular effects in land surface observations from satellites (EAGLE), and the ESA-funded programs SPECTRA. $\mathrm{He}$ has authored or coauthored more than 100 papers in international refereed journals. His current research interests include thermal infrared radiometry, parameterization of land surface processes at large scale, and assimilation of satellite data to land surface models.

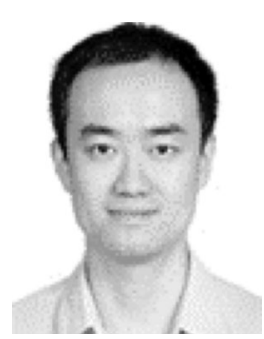

Hua Wu received the Ph.D. degree in cartography and geographical information system from the Institute of Geographic Sciences and Natural Resources Research, Chinese Academy of Sciences, Beijing, China, in 2010.

He is currently an Associate Research Fellow with the Institute of Geographic Sciences and Natural Resources Research, Chinese Academy of Sciences. His current research interests include the retrieval and validation of surface temperature and emissivities and scaling of remotely sensed products.

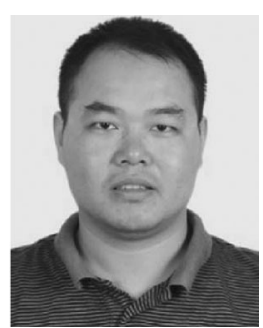

Si-Bo Duan received the Ph.D. degree in cartography and geographical information system from the Institute of Geographic Sciences and Natural Resources Research, Chinese Academy of Sciences, Beijing, China, in 2014.

He is currently an Associate Professor with the Institute of Agricultural Resources and Regional Planning, Chinese Academy of Agricultural Sciences, Beijing. His current research interests include the retrieval and validation of land surface temperature.

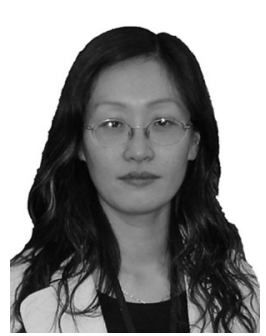

Xiaoning Song received the Ph.D. degree in cartography and geographical information system from Graduated University of Chinese Academy of Sciences, Beijing, China, in 2004

She is currently a Professor with the University of Chinese Academy of Sciences. Her current research interests include quantitative remote sensing and the application of remote sensing in ecological environment.

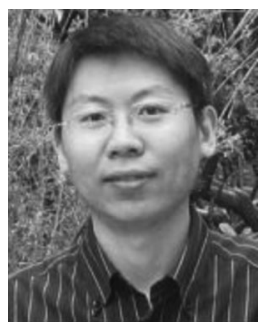

Guangjian Yan received the Ph.D. degree from the Institute of Remote Sensing Applications, Chinese Academy of Sciences, Beijing, China, in 1999.

$\mathrm{He}$ is currently a Professor with Beijing Normal University, Beijing. He has authored or coauthored more than 100 papers. His current research interests include multiangular and thermal infrared remote sensing. 